\title{
Studies on the treatment of surface water using rajma seeds
}

\author{
S. Babitha Merlin, M. Abirami, R. Suresh Kumar \\ Tagore Engineering College, Chennai, \\ Department of Civil Engineering \\ E-mail: babi.merlin@gmail.com
}

\begin{abstract}
Indiscriminate disposal of wastewater with suspended solids have led to higher amount of pollution to the natural water bodies. Turbidity removal becomes an essential part in the water treatment when surface water is used for drinking purpose, this can be achieved by means of coagulation process. Coagulation process is the dosing of a coagulant in water, resulting in the destabilization of negatively charged particles. Commercial coagulants which were widely used can synthesize by-products in turn may pollute the environment and deteriorate the ecosystem at a slow rate. So, now-a-days natural coagulants are used as a potential substitute because it's biodegradable, ecofriendly and non-toxic. In this study, the turbid surface water samples were treated using powdered seeds of Rajma (natural coagulant) followed by variations in dosage, settling time and $\mathrm{pH}$ were also studied. From the results obtained, it was found that the Rajma seeds powder achieved $48.80 \%$ efficiency for $0.5 \mathrm{~g} / \mathrm{l}$ of optimum dose at $\mathrm{pH} 6$ for 20 min settling time respectively.
\end{abstract}

Keywords: natural coagulant, turbidity, surface water

\section{Introduction}

The removal of colloidal and suspended particles present in water would be extremely beneficial as it would assuage the majority of problems associated with turbidity. The contaminated waters disrupt the aquatic life and reduce their reproductive capability [1].

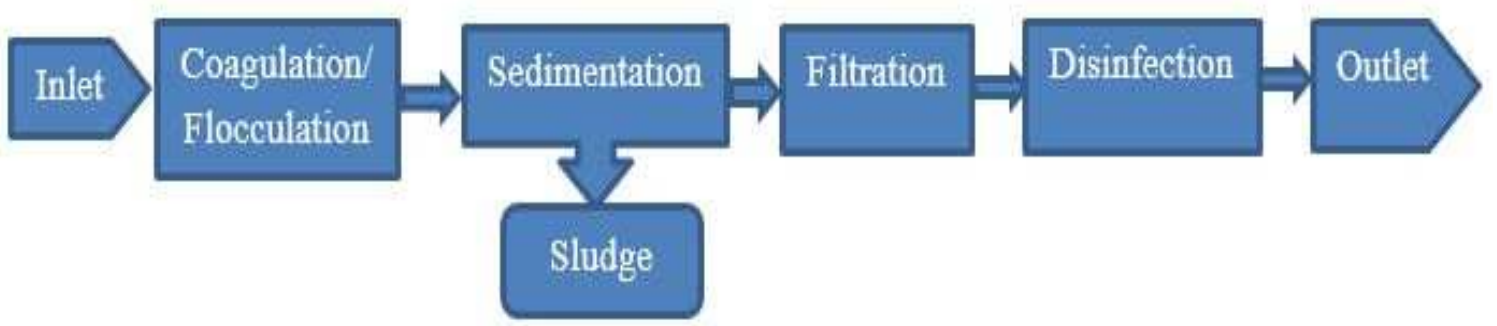

Figure 1: Conventional water treatment process 
Drinking water treatment involves a number of combined processes (Fig. 1) based on the quality of the water source such as turbidity, amount of microbial load present in water and the others include cost and availability of chemicals in achieving desired level of treatment. Generally drinking water treatment protocols consist of two major steps: coagulation/flocculation and disinfection. Commonly alum (Aluminium sulphate) is used as a coagulation agent, as it is efficient and relatively cost-effective in developed countries; while, disinfection is achieved by the addition of chemical disinfectants like chlorine-based compounds [12].

Control of the sources of water together with treatment of drinking water in remote areas where the infrastructure has not yet reached, is part of the solution to improve the life for many people. Good clarification has not always been obtained due to lack of knowledge on how the seed powder coagulates turbid water. On studying the seeds used in the traditional water treatment methods scientifically, it has been anticipated that achieved knowledge on the functionality of the seeds may not only provide benefits for the rural population, but also the urban water utilities which often produce insufficiently treated water [2].

Most particulate matter cannot settle by gravity and their sizes are so small that they pass through the pores of most common filtration media. Conventionally, the enmeshment and removal of the colloids in water could be achieved by coagulation, using certain chemical coagulants like alum. For many developing countries, this treatment process is not feasible because of the high costs involved and the difficulty in assessing chemical coagulants including alum. Various methods are used to make water safe and attractive to the consumer. The method employed depends on the character of the raw water. One of the problems with treatment of water is the large seasonal variation in turbidity. For the treatment of water, some traditional chemicals are used during the treatment of water to its various steps [3].

Commonly used chemicals for various treatment units are synthetic organic and inorganic substances. In most of the cases, these are expensive since they are required in higher dose and does not show cost effectiveness. The history of the use of natural coagulants is long. Natural organic polymers have been used for more than 2000 years in India, Africa, and China as effective coagulants and coagulant aids at high water turbidity. Research works by several researchers confirmed that natural coagulants are both economical and efficient [4].

Many coagulants are widely used in conventional water treatment processes, based on their chemical characteristics. These coagulants are classified into inorganic, synthetic organic polymers, and natural coagulants. Natural macromolecular coagulants are promising and have attracted the attention of many researchers because of their abundant source, low price, multipurposeness, and biodegradation [6].

Nowadays, there is a high demand to find an alternative coagulant which is preferably from natural, renewable sources and safe for human health. Several studies have been done on natural coagulants produced or extracted from plants, animals, or microorganisms. Moringa oleifera is one of the effective coagulants and has been tested to be used as a primary coagulant in water and wastewater treatment. Others type of natural coagulant such as cactus plant has been discovered to have the potential as coagulant [14]. 
Natural coagulants may be manufactured from plant seeds, leaves, and roots. These natural organic polymers are interesting because, comparative to the use of synthetic organic polymers [11] containing acryl amide monomers, there is no human health danger and the cost of these natural coagulants would be less expensive than the conventional chemicals alike since it is locally available in most rural communities of India [5 \& 13]. The studies were carried out to check the feasibility of Rajma seeds (natural coagulant) and to analyze the effect of varying parameters (dosage, settling time and $\mathrm{pH}$ ) for the treatment of surface water.

\section{Materials and Methods}

\subsection{Collection and Preparation of Natural Coagulants}

The Rajma (Cicer arietinum) was selected based on their abundant source, low price and biodegradability. The seeds were obtained from the local market, washed and dried in sunlight or room temperature. The dried seeds were then grinded to fine powder and stored in containers $[6,7,9,12]$.

\subsection{Sample Collection}

The surface water samples for analysis were collected from Periya Eri Lake, Rathinamangalam.

\subsection{Coagulation Studies}

The coagulation studies were carried out as batch process using jar test apparatus, accommodating a series of six beakers with six spindle steel paddles. For each beaker, 1000 $\mathrm{ml}$ of sample was taken to which varying amount of coagulant dosage $(0.25,0.5,0.75,1$, $1.25,1.5 \mathrm{~g} / \mathrm{L})$ was added to the respective beakers followed by variation in $\mathrm{pH}(5,6,7,8,9$, 10) and settling time $(10,20,30,4050,60$ minutes) were done. Then the apparatus was switched on and the speed of paddles were adjusted to about $100 \mathrm{rpm}$ thus rapid mixing of about 1-2 minutes was done. After rapid mixing, the speed of paddles was reduced to about 30 to $40 \mathrm{rpm}$ followed by slow mixing for 20 minutes. After slow mixing, the apparatus was switched off and the samples were allowed to settle. Initially the dosage of Rajma seeds was varied to find the optimum dosage, after that the $\mathrm{pH}$ was varied to determine the optimum $\mathrm{pH}$ by keeping the optimum dosage as constant, then the optimum Dosage and optimum $\mathrm{pH}$ were kept constant to find the optimum settling time by varying the settling time. The treated samples were then analyzed for turbidity level $[8 \& 10]$ with respect to the effect of varying parameters and the removal efficiencies were obtained.

\section{Results and Discussion}

The initial turbidity of sample was found to be 129.7 NTU. The dosage was varied in the range from $0.25 \mathrm{~g} / \mathrm{l}$ to $1.25 \mathrm{~g} / \mathrm{l}$ followed by variation in $\mathrm{pH}$ and settling time from which the optimum was determined. The treated samples (Fig. 2) were then analyzed for turbidity removal. The results were shown in Fig. 3, Fig. 4 and Fig. 5. 


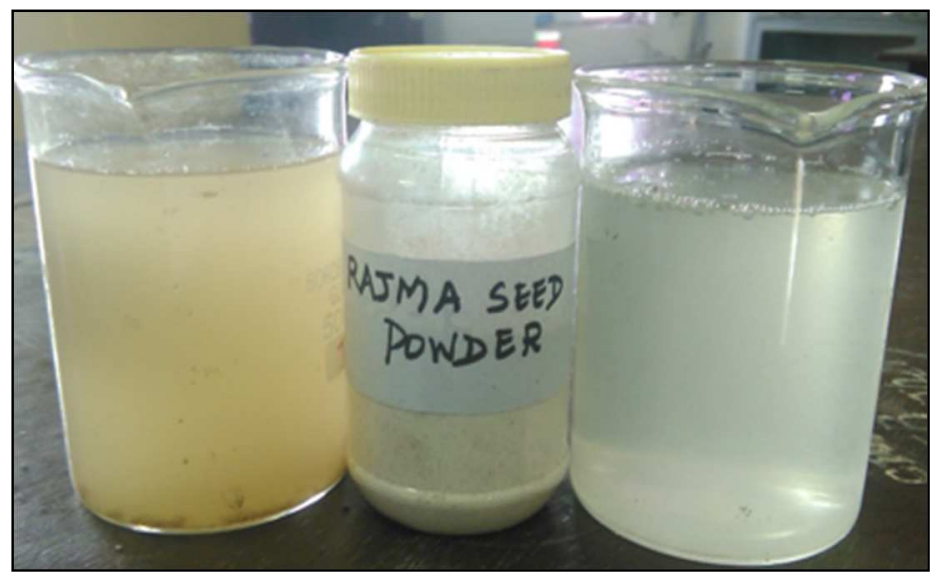

Figure 2: Sample before and after treatment using rajma seeds powder

Fig. 3 shows the effect of dosage on turbidity removal. It can be seen that there is an initial increase in removal efficiency of turbidity with dosage up to $0.5 \mathrm{~g} / \mathrm{L}$. Any further increase in dosage lead to a steady reduction in removal efficiency. The maximum removal of $34.08 \%$ was achieved at a dosage of $0.5 \mathrm{~g} / \mathrm{L}$.

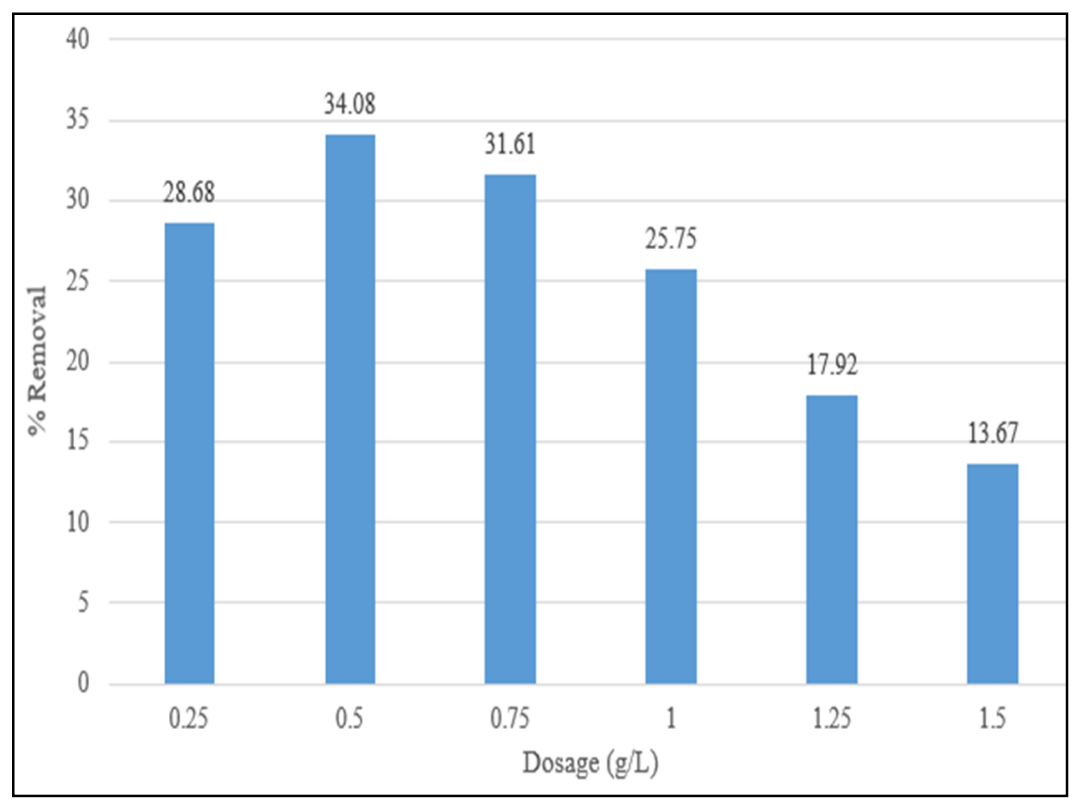

Figure 3: Effect of dosage on turbidity removal

Fig. 4 shows the effect of $\mathrm{pH}$ on turbidity removal for an optimum dosage of $0.5 \mathrm{~g} / \mathrm{L}$. It can be seen that there is an initial increase in removal efficiency of turbidity with $\mathrm{pH}$ up to $\mathrm{pH} 6$. Any further increase in $\mathrm{pH}$ lead to a general reduction in removal efficiency. The maximum removal efficiency of $59.21 \%$ was achieved at $\mathrm{pH}$ 6. On final examination, it was observed that the least removal efficiency was obtained at neutral $\mathrm{pH}$ of 7 . The removal efficiency increased on either side acidic or alkaline. However, slightly acidic $\mathrm{pH}$ produces the maximum removal efficiency. 


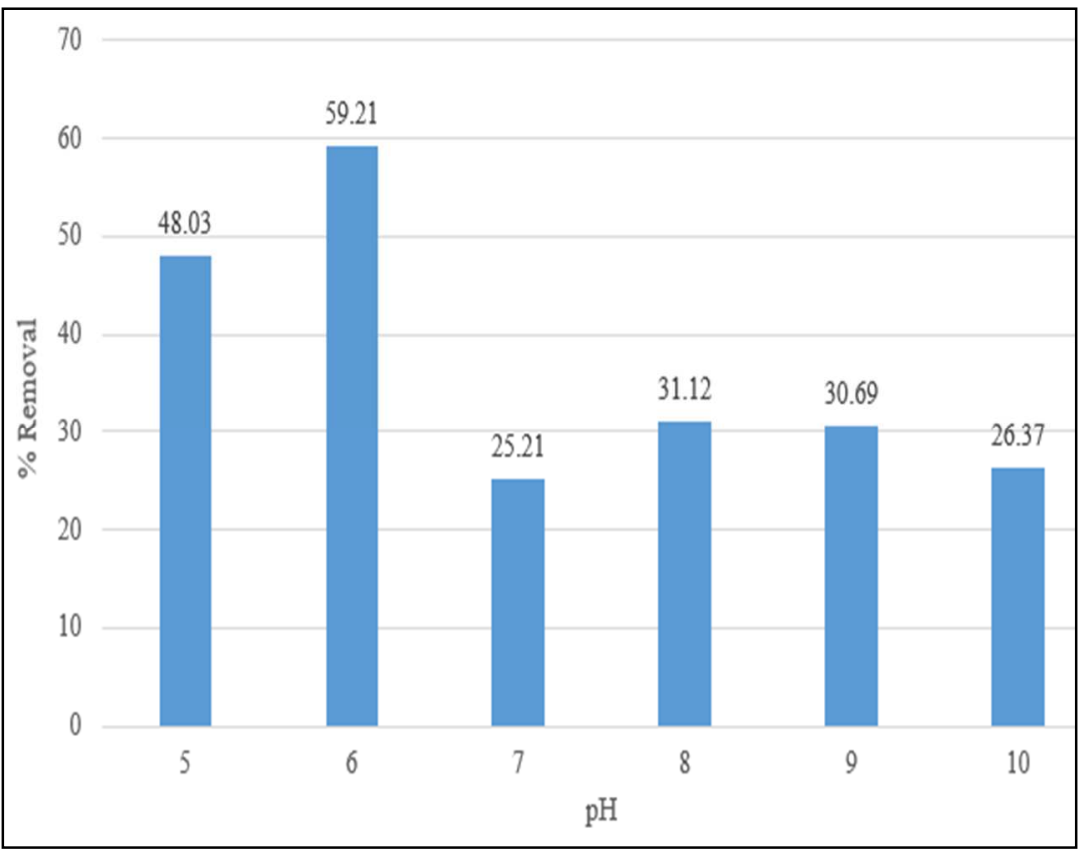

Figure 4: Effect of $\mathrm{pH}$ on turbidity removal (Dosage - $0.5 \mathrm{~g} / \mathrm{L}$ )

Fig. 5 shows the effect of settling time on turbidity removal for an optimum dosage of $0.5 \mathrm{~g} / \mathrm{L}$ and $\mathrm{pH}$ 6. It was observed that there is an initial increase in removal efficiency of turbidity with settling time up to 20 minutes. As the settling time increases there was found to be a reduction in the removal efficiency. The maximum removal efficiency of $48.80 \%$ was achieved for settling time of 20 minutes. It is clear that an optimal settling time rather than maximum settling time is essential for achieving turbidity removal.

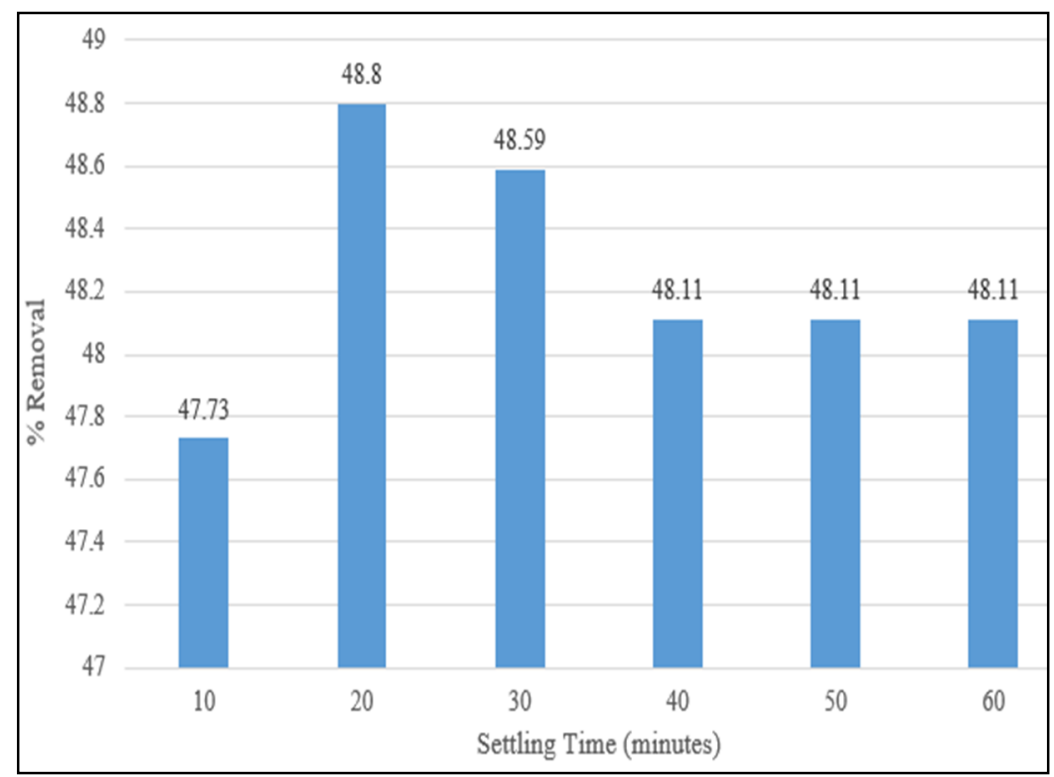

Figure 5: Effect of settling time on turbidity removal (Dosage $-0.5 \mathrm{~g} / \mathrm{L}, \mathrm{pH}-6$ ) 


\section{Conclusion}

The application of natural coagulant (Rajma seeds) on surface water treatment was examined in this study. The surface water was characterized by high concentration of suspended particles. On varying the coagulant dosage, $\mathrm{pH}$ and settling time, these particles gets easily dissolved and settled along with the coagulants added. Thus, it was observed that Cicer arietinum (Rajma seeds) has shown $48.80 \%$ removal efficiency for $0.5 \mathrm{~g} / \mathrm{l}$ of optimum dosage at $\mathrm{pH} 6$ in 20 min of settling time.

From the investigation, it is clear that the parameters dosage, $\mathrm{pH}$ and settling time will definitely influence the removal efficiency of turbidity. Based on the investigation, it can be concluded that maximum turbidity removal can be achieved at lower doses of natural coagulant's namely Rajma seeds. It is also evident that a slightly acidic environment will greatly improve the removal efficiency. The turbidity removal can be maximized by providing optimal settling time rather than maximum settling time.

Further studies are required to confirm its efficacy as a significant natural coagulant. The findings suggested that the parameters like slow mixing time and rapid mixing time can also be varied, studies can also be carried for the treatment of wastewater. For better efficacy, a mixture of one or more natural coagulants can also be used.

\section{References}

[1] Egbuikwem P.N. and Sangodoyin A.Y. (2013). Coagulation efficacy of Moringa Oleifera seed extract compared to alum for removal of turbidity and E. coli in three different water sources. European International Journal of Science and Technology, Vol. 2(7).

[2] Annika Blix. (2011). Enhancing the capacity of seeds as turbidity removal agents in water treatment. Department of Land and Water Resources Engineering, Royal Institute of Technology, Sweden.

[3] Asrafuzzaman A. N. M., Fakhruddin and Alamgir Hossain. (2011). Reduction of turbidity of water using locally available natural coagulants. International Scholarly Research Network, ISRN Microbiology.

[4] Phani Madhavi T. and Raj Kumar R. (2013). Utilisation of natural coagulant for reduction of turbidity from wastewater. International Journal of Chem Tech Research, Vol. 5(3), pp. 1119-1123.

[5] Jeyakumar P. (2014). Purification of pond water by natural seeds and dye water by synthetic coagulant. Journal of Chemical and Pharmaceutical sciences.

[6] Saritha Vara. (2012). Screening and evaluation of innate coagulants for water treatment: a sustainable approach. International Journal of Energy and Environmental Engineering, Vol. 3.

[7] Megat Ahmad Kamal Megat Hanafiah, Munirah Alias and Wan Khaima Azira Wan Mat Khalir. (2014). Enhanced adsorption of Pb (II) on chemically treated Neem (Azadirachta indica) leaf powder. Advanced Materials Research, pp. 128-133. 
[8] Birima A.H., Hammad H.A., Desa M.N.M and Muda Z.C. (2013). Extraction of natural coagulant from peanut seeds for treatment of turbid water. Centre for Storm Water and Geo Hazard Management, Earth and Environmental Science, Vol. 16.

[9] Chitteti Ramamurthy, Malige Uma Maheswari and Natarajan Selvaganabathy. (2012). Evaluation of eco-friendly coagulant from Trigonella foenum-graecum seed. Advances in Biological Chemistry, Vol. 2, pp. 58-63.

[10] Heinz Rembold. (1999). Traditional purification methods. Max-Planck Institute of Biochemistry.

[11] Hunter water. (2011). Fact sheet on Drinking water: Alum in water treatment.

[12] Ida Bodlund. (2013). Coagulant protein from plant materials: Potential water treatment agent. Royal Institute of Technology, pp. 1654-2312.

[13] Senthil Kumar M., Gopala Krishna G.V.T. and Sivasankar V. (2015). Coagulation performance evaluation of natural and synthetic coagulants in wastewater treatment. ARPN Journal of Engineering and Applied Sciences, Vol. 10(6).

[14] Shafad M. R., Ahamad I. S. and Idris A. (2013). A preliminary study on dragon fruit foliage as natural coagulant for water treatment. International Journal of Engineering Research \& Technology, Vol. 2(12), pp. 1057 - 1063. 